\title{
Small coronary vessel angioplasty: outcomes and technical considerations
}

\author{
This article was published in the following Dove Press journal: \\ Vascular Health and Risk Management \\ 9 October 2010 \\ Number of times this article has been viewed
}

\author{
Sudhir Rathore \\ Department of Cardiology, Atkinson \\ Morley wing, St George's Healthcare \\ NHS Trust, London, UK
}

\begin{abstract}
Small vessel $(<3 \mathrm{~mm})$ coronary artery disease is common and has been identified as independent predictor of restenosis after percutaneous coronary intervention. It remains controversial whether bare-metal stent (BMS) implantation in small vessels has an advantage over balloon angioplasty in terms of angiographic and clinical outcomes. Introduction of drug-eluting stent (DES) has resulted in significant reduction in restenosis and the need for repeat revascularization. Several DESs have been introduced resulting in varying reduction in outcomes as compared with BMS. However, their impact on outcomes in small vessels is not clearly known. It is expected that DES could substantially reduce restenosis in smaller vessels. Large, randomized studies are warranted to assess the impact of different DESs on outcomes in patients with small coronary arteries.
\end{abstract}

Keywords: small coronary arteries, coronary artery disease, stent, drug-eluting stent, restenosis

\section{Introduction}

Coronary artery disease (CAD) is the leading cause of mortality and morbidity in the Western world. ${ }^{1}$ Percutaneous coronary intervention (PCI) utilizing balloon angioplasty and stenting is a predominant treatment strategy for patients with CAD. Lesions involving the small coronary arteries (with a diameter of $<3 \mathrm{~mm}$ ) are the most relevant in terms of prevalence, and they account for around $40 \%-50 \%$ of all coronary stenosis. ${ }^{2}$ Atherosclerosis of small arteries remains a major challenge to revascularization procedures, as coronary artery bypass grafting is limited by high rates of technical failure, ${ }^{3}$ and PCI is associated with an increased risk of restenosis and adverse outcome. Small coronary vessel angioplasty remains the independent predictor of repeat revascularization and adverse cardiac events. ${ }^{2,4,5}$ Percutaneous treatment of CAD has evolved from percutaneous balloon angioplasty to bare-metal stent (BMS) and more recently to drug-eluting stent (DES) implantation. As compared with balloon angioplasty, BMS prevents both early elastic recoil and late vascular remodeling in large vessels $(>3 \mathrm{~mm}) .{ }^{6-10}$ However, this benefit is not shown in small coronary vessels $(<3 \mathrm{~mm}) .{ }^{11-14}$ Stent implantation results in arterial injury, initiating a vasculoproliferative cascade with smooth muscle cell proliferation and migration resulting in neointimal hyperplasia. The amount of neointimal hyperplasia is largely independent of vessel size, and thus, late luminal loss, an angiographic measure of neointimal hyperplasia, is similar across a wide range of vessel diameters. ${ }^{15,16}$ Also, small vessels are more prone to restenosis than larger vessels because they are less able to accommodate neointimal tissue without compromising blood flow. ${ }^{17}$
Correspondence: Sudhir Rathore Department of Cardiology, Atkinson Morley Wing, St George's Healthcare NHS Trust, London SWI7 0QT, UK Tel +44780 36I 5142

Email sudhirrathore@hotmail.com 
In this review, we describe the impact of balloon angioplasty, BMSs, and DESs on the outcomes after small vessel coronary intervention.

\section{BMS vs balloon angioplasty in small vessels}

Several randomized trials have compared stenting and percutaneous transluminal coronary angioplasty (PTCA), in terms of clinical and angiographic outcomes, in coronary arteries with a reference vessel diameter (RVD) of $<3 \mathrm{~mm}$. Agostoni et al ${ }^{18}$ evaluated these outcomes in a meta-analysis, and they included 13 studies involving 4,383 randomized patients: 2,097 to PTCA and 2,286 to stenting. The studies showing mortality, myocardial infarction (MI) rates, target lesion revascularization (TLR), and combined major adverse cardiac events (MACE) are shown in Table 1.

The mean age of patients in these studies was $62.1 \pm 10$ years, with $77.2 \%$ men and $28.9 \%$ with diabetes. BMSs were used in 6 trials (Park et al ${ }^{12}$ ISAR-SMART, BESMART, SISA, RAP, CHIVAS), whereas a stent coated with heparin
(SISCA, COAST, Kinsara et al) ${ }^{21}$ or silicon carbide (SVS) or phosphorylcholine (ISAR-SMART, LASMAL, LASMAL 11) was used in the remainder. RVD was $2.33 \pm 0.29 \mathrm{~mm}$ in the stent group and $2.31 \pm 0.29 \mathrm{~mm}$ in PTCA group. The mean lesion length was $10.1 \pm 5.2 \mathrm{~mm}$, and crossover rate was $22.2 \%$ among PTCA group. Postprocedural mean diameter stenosis and minimal luminal diameter were significantly better after stenting as compared with PTCA.

The follow-up period ranged from 6-16 months. Death and MI rates did not differ significantly between groups (1.3\% and $3.1 \%$ in the stent group vs $1.7 \%$ and $4.2 \%$ after PTCA, respectively). Stenting showed a significant reduction of the risk of TLR when compared with PTCA group (14.9\% vs $18.7 \%$, respectively). However, authors have mentioned that there was significant heterogeneity among the trials. Among the studies where optimal PTCA result (diameter stenosis $<20 \%$ ) was achieved, there was no difference in the repeat TLR rates (15\% vs $16.7 \%)$. On the contrary, among trials in which a suboptimal PTCA result was achieved, stenting resulted in significant reduction of repeat TLR rates

Table I Comparison of angiographic characteristics, death, MI, TLR, and MACEs, following BMS and balloon angioplasty

\begin{tabular}{|c|c|c|c|c|c|c|}
\hline \multirow[t]{2}{*}{$\overline{\text { Study }}$} & \multirow{2}{*}{$\begin{array}{l}\text { Total No. of } \\
\text { patients }\end{array}$} & \multirow[t]{2}{*}{ RVD (mm) } & \multicolumn{4}{|c|}{ BMS vs balloon angioplasty } \\
\hline & & & $\begin{array}{l}\text { Death (\%) } \\
\text { OR (95\% CI) }\end{array}$ & $\begin{array}{l}\text { MI (\%) } \\
\text { OR (95\% CI) }\end{array}$ & $\begin{array}{l}\text { TLR (\%) } \\
\text { OR ( } 95 \% \mathrm{CI})\end{array}$ & $\begin{array}{l}\text { MACE (\%) } \\
\text { OR }(95 \% \mathrm{CI})\end{array}$ \\
\hline \multirow[t]{2}{*}{ Park et al ${ }^{12}$} & 120 & $<3.0$ & 0.0 vs 0.0 & 1.6 vs 3.2 & 3.3 vs 5.0 & 5.0 vs 8.3 \\
\hline & & & NA & $0.49(0.04-5.57)$ & $0.66(0.11-4.07)$ & $0.58(0.13-2.54)$ \\
\hline \multirow[t]{2}{*}{ ISAR-SMARTII } & 404 & $2.0-2.8$ & 0.9 vs 1.5 & 3.4 vs 3.0 & 20.1 vs 16.5 & 23.0 vs 19.5 \\
\hline & & & $0.66(0.11-3.93)$ & $1.15(0.38-3.48)$ & $\mathrm{I} .27(0.77-2.1 \mathrm{I})$ & $1.28(0.79-2.06)$ \\
\hline \multirow[t]{2}{*}{$B E S M A R T^{13}$} & 381 & $<3.0$ & 0.52 vs 2.1 & 4.6 vs 5.8 & 13.5 vs 23.8 & 17.1 vs 29.6 \\
\hline & & & $0.24(0.03-2.19)$ & $0.80(0.32-1.97)$ & $0.50(0.29-0.85)$ & $0.49(0.30-0.80)$ \\
\hline \multirow[t]{2}{*}{ SISA 19} & 351 & $2.3-2.9$ & 0.6 vs 0.5 & 4.1 vs 9.8 & 20.7 vs 24.7 & 20.7 vs 25.2 \\
\hline & & & $1.08(0.07-17.36)$ & $0.39(0.16-0.97)$ & $0.80(0.48-|.3|)$ & $0.77(0.47-1.27)$ \\
\hline \multirow[t]{2}{*}{$\operatorname{SISCA}^{14}$} & 145 & $2.1-3.0$ & I. 3 vs $1.4,0.96$ & 2.7 vs 1.4 & 9.4 vs 22.5 & 9.4 vs 23.9 \\
\hline & & & $(0.06-15.63)$ & $1.94(0.17-21.93)$ & $0.36(0.14-0.94)$ & $0.33(0.13-0.86)$ \\
\hline \multirow[t]{2}{*}{ COAST $^{20}$} & 588 & $2.0-2.6$ & 1.0 vs 0.0 & 0.5 vs 1.0 & 10.6 vs 14.3 & II.7 vs 15.3 \\
\hline & & & $4.52(0.24-84.33)$ & $0.49(0.07-3.53)$ & $0.71(0.43-1.19)$ & $0.73(0.44-1.20)$ \\
\hline \multirow[t]{2}{*}{ Kinsara et $\mathrm{al}^{21}$} & 202 & $<2.5$ & I.0 vs 0.0 & 6.2 vs 6.6 & 12.5 vs 23.5 & 19.7 vs 30.1 \\
\hline & & & $3.35(0.13-83.11)$ & $0.94(0.3|-2.9|)$ & $0.64(0.45-0.92)$ & $0.57(0.30-1.09)$ \\
\hline \multirow[t]{2}{*}{ SVS $^{22}$} & 496 & $2.0-3.0$ & 2.4 vs 2.4 & 4.8 vs 3.6 & 18.8 vs 14.2 & 23.2 vs 18.6 \\
\hline & & & $0.98(0.31-3.09)$ & $\mathrm{I} .33(0.55-3.2 \mathrm{I})$ & $\mathrm{I} .40(0.97-2.25)$ & $1.31(0.85-2.03)$ \\
\hline \multirow[t]{2}{*}{$\mathrm{RAP}^{23}$} & 426 & $2.2-2.7$ & 0.47 vs I. 4 & 0.9 vs 1.4 & 12.2 vs 22.4 & 13.6 vs 25.2 \\
\hline & & & $0.33(0.3-3.23)$ & $0.67(0.11-4.06)$ & $0.48(0.29-0.91)$ & $0.47(0.29-0.77)$ \\
\hline \multirow[t]{2}{*}{ CHIVAS $^{24}$} & 302 & $<3.0$ & 0 vs 2.5 & 0 vs 0.6 & 10.8 vs 14.9 & 10.8 vs 18.1 \\
\hline & & & $0.1 I(0.0 \mathrm{I}-2 . \mathrm{II})$ & $0.34(0.01-8.53)$ & $0.69(0.35-1.37)$ & $0.55(0.28-1.06)$ \\
\hline \multirow[t]{2}{*}{ ISAR-SMART II ${ }^{25}$} & 502 & $<2.5$ & 3.9 vs 3.6 & 3.9 vs 4.0 & 20.1 vs 20.5 & 26.8 vs 26.9 \\
\hline & & & $1.10(0.44-2.75)$ & $0.98(0.40-2.91)$ & $0.98(0.63-1.5 \mathrm{I})$ & $1.0(0.67-1.48)$ \\
\hline \multirow[t]{2}{*}{ LASMAL $^{26}$} & 246 & $2.0-2.9$ & 0.8 vs 3.27 & 5.6 vs 9.0 & I 5.3 vs 20.4 & 16.9 vs 27.8 \\
\hline & & & $0.24(0.03-2.18)$ & $0.60(0.22-1.6 \mathrm{I})$ & $0.70(0.36-1.35)$ & $0.53(0.29-0.97)$ \\
\hline \multirow[t]{2}{*}{ LASMAL $\|^{27}$} & 220 & $2.0-2.9$ & 1.8 vs $1.8,0.98$ & 6.3 vs 7.3 & 15.3 vs 14.6 & 18.0 vs 22.0 \\
\hline & & & $(0.14-7.10)$ & $0.85(0.30-2.43)$ & $1.05(0.50-2.20)$ & $0.78(0.40-\mid .5 \mathrm{I})$ \\
\hline \multirow[t]{2}{*}{ Total } & 4,383 & $<3.0$ & 1.3 vs 1.7 & 3.1 vs 4.2 & 15.5 vs 18.8 & 18.2 vs 22.7 \\
\hline & & & $0.81(0.48-1.36)$ & $0.90(0.58-1.1 \mathrm{I})$ & $0.76(0.61-0.95)$ & $0.7 \mid(0.57-0.90)$ \\
\hline
\end{tabular}

Abbreviations: MI, myocardial infarction; TLR, target lesion revascularization; MACEs, major adverse cardiac events; BMS, bare-metal stent; RVD, reference vessel diameter; OR, odds ratio; $\mathrm{Cl}$, confidence interval. 
(14.8\% vs 20.4\%). MACE rates were higher in PTCA group (17.6\% vs $22.7 \%$ ) and were mainly driven by repeat TLR. Angiographic follow-up was performed in $81.9 \%$ of the patients, and the angiographic restenosis was seen in $27.8 \%$ patients in stent group compared with $35.8 \%$ in the PTCA group with significant heterogeneity. Optimal PTCA group has similar angiographic restenosis rates as stent group.

Therefore, stenting appears safe with small vessel CAD and significantly reduces angiographic restenosis and repeat revascularization rates. However, optimal PTCA in this group of patients have achieved comparable results to BMS implantation. The revascularization rates remain high with PTCA or BMS implantation in patients with small vessel CAD.

\section{BMS vs DES in small vessels Paclitaxel-eluting stents vs BMS in small vessels}

There are no dedicated trials comparing paclitaxel-eluting stent (PES) and BMS in small coronary arteries. However, large PES trials have described substudy results in small vessels. In TAXUS IV trial, ${ }^{28}$ there were 176 patients with RVD $<2.5 \mathrm{~mm}$ randomized to PES and BMS. Angiographic restenosis rate and 12-month TLR rate in the PES group were significantly lower than that in the BMS group, respectively (10.2\% and $5.6 \%$ vs $38.5 \%$ and $20.6 \% ; P<0.001$ ).

In the TAXUS $\mathrm{V}$ trial, ${ }^{29}$ more patients with complex lesions were investigated. In the patient group treated with the 2.25-mm stent, both PES and BMS have similar acute outcomes. However, at the 9-month follow-up, the angiographic restenosis rates and TLR rates were significantly lower in PES group as compared with BMS group (31\% and $10.4 \%$ vs $49.4 \%$ and $21.5 \% ; P=0.01$ and $P=0.03$, respectively). In this post hoc analysis, 9-month MACE rates were $18.9 \%$ vs $26.9 \% ; P=0.23$, which did not reach statistical significance.

In the TAXUS VI trial, ${ }^{30}$ angiographic and clinical outcomes were followed up to 9 months in complex subset of patients. In the subgroup with small vessels (RVD $<2.5 \mathrm{~mm}$ ), in-stent late lumen loss was considerably smaller in the PES group than in the BMS group $(0.23 \pm 0.45 \mathrm{~mm}$ vs $0.95 \pm 0.52 \mathrm{~mm} ; P<0.0001)$, explaining the significantly lower angiographic restenosis and TLR observed in the PES group $(7.3 \%$ and $5.0 \%$ vs $40.4 \%$ and $29.7 \%$, respectively; $P<0.001)$.

Taking these TAXUS subgroup results in consideration, PES seems to confer clinical benefits in patients with small vessels compared with BMS. This is mainly because of marked inhibition of neointimal hyperplasia by PES. These results could have been influenced by the release kinetics of drug, polymer used, and stent platform. TAXUS ${ }^{\circledR}$ Express $^{\circledR}$ stent (Boston Scientific Inc, Natick, Massachusetts) was used in TAXUS IV trial, and TAXUS Express2 stent was used in TAXUS V and TAXUS VI trials. TAXUS Express stent consists of balloon-expandable stent with Translute ${ }^{\mathrm{TM}}$ polymer-coating containing paclitaxel (Boston Scientific Inc). TAXUS Express2 stent is composed of a balloon-expandable Express 2 stent with a triblock copolymer coating with paclitaxel. The release kinetics of drug was slow in TAXUS IV and $\mathrm{V}$ trials, whereas this was moderate in TAXUS VI trial.

\section{Sirolimus-eluting stent vs BMS in small vessels}

Sirolimus-eluting stent (SES) has been tested in pivotal SIRIUS trial, ${ }^{31}$ and the substudy involving small vessels $(\leq 2.75 \mathrm{~mm}$ ) showed significantly lower TLR rates with SES as compared with BMS (6.6\% vs $22.3 \% ; P<0.0001)$. Similarly, angiographic substudy ${ }^{32}$ has shown significantly lower restenosis in SES group (17.6\% vs 42.7\%; $P<0.001)$.

The SES-SMART trial, ${ }^{33}$ which enrolled patients with small vessels (mean RVD $=2.2 \mathrm{~mm}$ ), indicated that the incidence of TLR and MACE in the SES arm was significantly lower compared with BMS arm (7.0\% and 9.3\% vs $21.1 \%$ and $31.3 \% ; P=0.002$ and $P<0.001$, respectively). Angiographic restenosis in the SES arm was also significantly lower compared with the BMS arm $(9.8 \%$ vs $53.1 \%, P<0.001)$.

Lee et $\mathrm{al}^{34}$ evaluated the predictive factors for restenosis following implantation of SES in small coronary arteries $(<2.8 \mathrm{~mm})$ in an observational study. They identified lesion length and restenotic lesions as independent predictors of angiographic restenosis in small vessels.

\section{Zotarolimus-eluting stent vs BMS in small vessels}

ENDEAVOR program has assessed the efficacy of zotarolimus-eluting stent (ZES) in patients with CAD. ENDEAVOR II $^{35}$ trial has randomly assessed outcomes after ZES and BMS in patients with native CAD. In a subgroup analysis of patients who had angiographic follow-up at 8 months, results were reported for 371 patients with RVD $<3 \mathrm{~mm}$. There were significantly less angiographic restenosis rates with the use of ZES in both $<2.5-\mathrm{mm}$ and $2.5-3 \mathrm{~mm}$ group as compared with BMS (18.2\% vs $38.6 \%$; odds ratio $[\mathrm{OR}]=0.47 ; 95 \%$ confidence interval $[\mathrm{CI}]: 0.28-0.79$ in $<2.5$-mm group and $4.6 \%$ vs $35.1 \%$; OR $=0.13 ; 95 \% \mathrm{CI}$ : $0.05-0.32$ in $2.5-3.0 \mathrm{~mm}$ group, respectively). They have also reported significantly less TLR rate with the use of ZES as compared with BMS (7.2\% vs $16.5 \%$ in $<2.5$-mm group and $3.0 \%$ vs $11.5 \%$ in $2.5-3.0 \mathrm{~mm}$ group). 


\section{PES vs SES in small vessels}

There is limited information available comparing SES and PES in small vessels. Some trials comparing the outcomes in small vessels are shown in Table 2. ISAR-SMART $3^{36}$ was the first head-to-head trial comparing SES and PES. This trial showed significantly less angiographic restenosis and TLR rates with the use of SES as compared with PES (11.4\% and $6.6 \%$ vs $19.0 \%$ and $14.7 \%$, respectively).

More recently, subgroup analysis of SIRTAX trial, ${ }^{37}$ which included patients with RVD $<2.75 \mathrm{~mm}$ was reported. In patients with small vessel stents, SES reduced MACE by $55 \%(10.4 \%$ vs $21.4 \% ; P=0.004)$, mainly driven by a $69 \%$ reduction of TLR rate $(6.0 \%$ vs $17.7 \% ; P=0.001)$. However, there were no significant differences with respect to death and MI.

There are two nonrandomized trials that have been performed comparing SES and PES in small coronary vessels. Park et $a{ }^{38}$ have performed retrospective study involving 197 patients with RVD of nearly $2.45 \mathrm{~mm}$ and reported lower angiographic restenosis and TLR rates with the use of SESs (6.7\% and $3.3 \%$ vs $27.7 \%$ and $14.4 \% ; P<0.01$ ). Another RESEARCH and T-SEARCH ${ }^{39,40}$ registry adopted a nonrandomized design and evaluated outcomes in patients treated with SES and PES in small coronary vessels (RVD $=2.25 \mathrm{~mm}$ ). The incidence of 12-month TLR and MACE was numerically more frequent with the use of PES, but they did not reach statistical significance (11.1\% and $18.9 \%$ vs $6.5 \%$ and $9.3 \%$; $P=0.31)$ and $P=0.06$, respectively.

\section{ZES vs PES in small vessels}

ENDEAVOR IV ${ }^{41}$ compared outcomes following implantation of ZES and PES in patients with CAD. In a subgroup analysis involving small vessels $(<2.5 \mathrm{~mm})$, there was significantly less target vessel failure at 12 months with the use of ZES as compared with PES (8.3\% vs $13.4 \%$; OR $=0.62 ; 95 \%$
CI: 0.37-1.03). However, there was no difference observed between PES and ZES in $2.5-3 \mathrm{~mm}$ group ( $8.8 \%$ vs $7.5 \%$; $\mathrm{OR}=1.18 ; 95 \%$ CI: 0.69-2.04).

\section{Everolimus-eluting stent vs PES in small vessels}

SPRIT IV ${ }^{42}$ trial has compared the efficacy of everolimuseluting stent (EES) and PES in patients with CAD. In a whole cohort, 1,352 patients were treated for small vessel disease $(\leq 2.75 \mathrm{~mm})$. In this subgroup analysis, there was significantly less occurrence of target vessel failure with the use of EES as compared with PES ( $3.9 \%$ vs $6.8 \%$; OR $=0.57$; 95\% CI: 0.35-0.91).

\section{Biolimus-eluting stent vs SES in small vessels}

LEADERS trial ${ }^{43}$ compared biolimus-eluting stent (BES) with biodegradable polymer and SES with durable polymer in patients with CAD. In a substudy, investigators have assessed the impact of vessel size on outcomes with these two different stent strategies. All-comer patients (1,707 patients) were included in the study, and comparison was done between vessel size $<2.75 \mathrm{~mm}$ ( $50.0 \%$ of the total cohort) and $>2.75 \mathrm{~mm}$. There was no significant difference between TLR rate $(9.6 \%$ vs $7.4 \% ; P=0.26)$ and MACE $(12.1 \%$ vs $11.8 \% ; P=0.89)$ in both BES and SES arms. However, the TLR rate ( $9.6 \%$ vs $2.6 \%)$ and MACE $(12.7 \%$ vs $7.1 \%)$ were significantly higher in small vessels as compared with large vessels in the BES arm.

\section{Summary of impact of DES in small vessels}

As evident from the aforementioned studies, the outcomes in small coronary arteries have improved following the introduction of DESs. TLR rate has improved from

Table 2 Comparison of angiographic characteristics, death, MI, TLR, and MACEs, following SES and PES

\begin{tabular}{|c|c|c|c|c|c|c|}
\hline \multirow[t]{2}{*}{ Study } & \multirow{2}{*}{$\begin{array}{l}\text { Total No. of } \\
\text { patients }\end{array}$} & \multirow[t]{2}{*}{ RVD (mm) } & \multicolumn{4}{|l|}{ SES vs PES } \\
\hline & & & Death (\%) & MI (\%) & TLR (\%) & MACE (\%) \\
\hline \multirow[t]{2}{*}{ ISAR-SMART $3^{36}$} & 360 & $<2.75$ & I.7 vs 2.2 & 3.9 vs 3.3 & 6.6 vs 14.7 & \\
\hline & & & $P=0.99$ & $P=0.78$ & $P=0.008$ & \\
\hline \multirow[t]{2}{*}{ Park et $\mathrm{al}^{38}$} & 197 & $<2.75$ & 0 vs 0 & 12.4 vs 13.2 & 3.3 vs 14.4 & I 5.7 vs 27.6 \\
\hline & & & $P=1$ & $P=0.54$ & $P<0.01$ & $P<0.01$ \\
\hline RESEARCH and & 199 & $<2.25$ & 0.9 vs 4.3 & 2.8 vs 7.8 & 6.5 vs II.I & 9.3 vs 18.9 \\
\hline T-SEARCH 39,40 & & & $P=0.18$ & $P=0.19$ & $P=0.31$ & $P=0.06$ \\
\hline \multirow[t]{3}{*}{ SIRTAX ${ }^{37}$} & 370 & $<2.75$ & 6.0 vs 5.4 & 3.8 vs 3.7 & 6.0 vs 17.7 & I0.4 vs 20.4 \\
\hline & & & $O R=1.10 ; 95 \%$ & $\mathrm{OR}=1.01 ; 95 \%$ & $\mathrm{OR}=0.3 \mathrm{I} ; 95 \%$ & $O R=0.45 ; 95 \%$ \\
\hline & & & $\mathrm{Cl}, 0.47-2.60$ & $\mathrm{Cl}, 0.35-2.88$ & $\mathrm{Cl}, 0.16-0.62$ & $\mathrm{Cl}, 0.26-0.78$ \\
\hline
\end{tabular}

Abbreviations: MI, myocardial infarction; TLR, target lesion revascularization; MACEs, major adverse cardiac events; RVD, reference vessel diameter; SES, sirolimus-eluting stent; PES, paclitaxel-eluting stent; OR, odds ratio; Cl, confidence interval. 
$20 \%-30 \%$ in the BMS era to around $10 \%$ with the usage of various DESs. This still remains higher as compared with other subgroups of CAD. Among the various DESs available, the TLR rate is relatively low (3\%-7\%) with the use of EES and SES as compared with PES and ZES (8\%-13\%). These results are biologically plausible because a reduction in luminal diameter by a constant amount of neointimal hyperplasia results in proportionally higher-grade diameter stenosis in small vessels compared with large vessels. Moreover, EES and SES have been invariably shown to afford lower late luminal loss in the trials $(0.14 \pm 0.41 \mathrm{~mm}$ for EES in SPIRIT $\mathrm{III}^{44}$ trial and $0.16 \pm 0.30 \mathrm{~mm}$ for SES in pivotal trials) as compared with higher late luminal loss with the use of ZES and PES $(0.67 \pm 0.49 \mathrm{~mm}$ for ZES and $0.42 \pm 0.50 \mathrm{~mm}$ for PES in ENDEAVOR IV and $0.61 \pm 0.46 \mathrm{~mm}$ in ENDEAVOR III), ${ }^{45}$ and a late luminal loss is an established marker to discriminate between different stent types. ${ }^{46}$

\section{Influence of stent strut thickness on outcomes in small vessels}

The mechanical differences of the BMS and the DESs may affect the outcomes in small coronary arteries. Briguori et $\mathrm{al}^{47}$ have shown that strut thickness was an independent predictor of angiographic restenosis in small coronary arteries $(\mathrm{RVD}=2.75-2.99 \mathrm{~mm})$; thinner-strutted stents were associated with lower incidence of restenosis than thicker-strutted stents.

Brambilla et $\mathrm{al}^{48}$ have assessed that in a prospective, multicentre registry, the impact of thin-strut chrome-cobalt stent (Mini VISION-strut size $0.081 \mathrm{~mm}$ ) angiographic and clinical outcomes in small coronary vessels. The average RVD was $2.41 \pm 0.41 \mathrm{~mm}$, and the 6 months MACE was $11.6 \%$, death $2.9 \%$, MI $2.9 \%$, and TLR $5.8 \%$. These outcomes are comparable with DES outcomes.

TAXUS ATLAS Small Vessel (SV) program ${ }^{49}$ is a multicentre study comparing the performance of the thinstrut $(0.095 \mathrm{~mm})$ TAXUS Liberte ${ }^{\circledR} 2.25-\mathrm{mm}$ stent (Boston Scientific Inc) in small vessels. This study compared the outcomes following implantation of TAXUS Liberte and TAXUS Express (0.132-mm strut size) stents in small vessels. TAXUS Liberte significantly reduced the rate of 9-month angiographic restenosis $(18.5 \%$ vs $32.7 \% ; P=0.02)$ and 12 -month TLR $(6.1 \%$ vs $16.9 \% ; P=0.0003)$ as compared with TAXUS Express stents. This TAXUS liberte (Atom ${ }^{\mathrm{TM}}$; Boston Scientific Inc) stent was specially designed for small vessels $(<2.25 \mathrm{~mm})$ and was approved by the US Food and Drug Administration for the treatment. This stent has 27-inch thinner struts, and the unique, uniform repeating cell geometry supports even drug distribution and delivery. This stent also has lowest stent crossing and tip profile making it a more trackable stent delivery system.

\section{Safety issue following small vessel DES implantation}

Since DESs were approved, these devices have been implanted in a large number of patients with CAD and with off-label indications including small vessels. Their use seems to be safe. However, issue of stent thrombosis has been one of the concerns. Although BMS implantation in small vessels had been previously cited as a risk factor for stent thrombosis, ${ }^{50-52}$ improved techniques of optimal stent deployment and dual antiplatelet therapy appear to have largely resolved this problem so that the risk of stent thrombosis of BMS in small vessel stenting now seems to be similar to that in large vessel stenting. ${ }^{53,54}$

DES implantation in small vessels may increase the risk of stent thrombosis. The incidence of stent thrombosis in small vessel DES implantation has not been shown to differ between PES and BMS or SES. In a subanalysis conducted in the TAXUS $\mathrm{V}^{29}$ clinical trial, both acute and late stent thrombosis rates were similar between PES and BMS ( $0.9 \%$ vs $1.1 \%$ and $1.0 \%$ vs $1.1 \% ; P=1.00$ and $P=1.00$, respectively). In ISAR-SMART $3^{36}$ trial and a study by Park et $\mathrm{al}^{38}$ no acute stent thrombosis was reported in both SES and PES arms, whereas there was no information about late stent thrombosis in either trial. In a subanalysis of the RESEARCH and T-SEARCH ${ }^{39,40}$ registries, $2.2 \%$ of patients had acute stent thrombosis in the PES arm; no thrombosis was observed in the SES $\operatorname{arm}(P=0.21)$. No late stent thrombosis occurred in either arm. In SIRTAX ${ }^{37}$ trial there was similar stent thrombosis seen in SES and PES arms in small vessels (2.2\% vs $2.7 \%$; $P=0.75$, respectively). This was similar to the stent thrombosis rates seen in large vessels $(1.9 \%$ vs $3.3 \% ; P=0.35)$ with the use of SES and PES, respectively. Lee et $\mathrm{al}^{34}$ have reported the late stent thrombosis of $0.4 \%$ up to 20 months following implantation of SES in small vessels.

However, late stent thrombosis is multifactorial, and the limited data available so far have shown similar rates with the use of DES.

\section{Factors predictive of adverse outcome after DES in small vessels}

Revascularization of small coronary arteries has been problematic because of high risk of restenosis. Before the introduction of DES, the restenosis rate in these lesions was very high, ranging from $30 \%-50 \%$, and there was 
only marginal benefit from stent implantation. However, DESs have markedly reduced the risk of restenosis, and their benefits are evident in small vessels. Small vessel disease still remains because of DES failure as compared with other groups. Lee et $\mathrm{a}^{34}$ have evaluated the predictive factors of adverse outcome following implantation of SES in a consecutive series of 1,092 patients with reference vessel size $<2.8 \mathrm{~mm}$. They have reported significant correlation between restenosis rate and lesion length, and restenosis rate was highest $(29.4 \%)$ in patients with very long lesions (>60 mm). Multivariate analysis showed that lesion length $(\mathrm{OR}=1.04 ; 95 \% \mathrm{CI}: 1.02-1.05 ; P<0.001)$ and in-stent restenotic lesions ( $\mathrm{OR}=3.38 ; 95 \% \mathrm{CI}: 1.80-6.35 ; P<0.001)$ were significant predictors of restenosis, but diabetes was not shown to be significant predictor of restenosis $(\mathrm{OR}=0.79$, 95\% CI: $0.47-1.33, P=0.378$ ).

Small vessel disease has become more common, and the proportion of patients requiring coronary intervention is likely to further increase. However, these patients have higher clinical and angiographic restenosis rates following small vessel angioplasty as shown in the aforementioned data. The risk of complications and restenosis in many of these patients are increased by other factors, particularly diffuse disease and diabetes mellitus. Although BMS have an advantage in acute gain compared with balloon angioplasty, the former results in more late loss due to neointimal overgrowth. This tissue encroachment presents a greater problem in small than in large vessels because it leaves less room for the lumen in the former. Therefore, using BMS, the long-term results of small vessel stenting were disappointing, and provisional stenting was considered a better option. The use of DESs in small coronary arteries, however, has reduced the rate of restenosis in comparison to BMSs. Various types of DESs are widely used in clinical practice. In head-to-head studies, the SES and EES have shown lower rate of late lumen loss as compared with PES and ZES, suggesting that the former group may be more effective in preventing restenosis in high-risk patients.

\section{Future directions in small vessel coronary angioplasty}

A number of stent-related properties, including stent configuration, strut thickness, and stent coating, can affect the long-term clinical outcome. Many trials have shown that the mesh-wire and coil-related stent designs suffer from a significantly higher risk of restenosis compared with the tubular or multicellular stent design. Studies have shown that stent with less strut-strut intersections (Multilink stent) is associated with the most favorable angiographic and clinical outcomes. ${ }^{55}$ The design, material composition, surface features of the stent, and stent deployment technique affect strongly the acute performance of the stent, risk of stent thrombosis, degree of vascular response, and subsequent risk of in-stent restenosis.

The availability of new, highly biocompatible, and more radiovisible alloys with the same if not superior tensile strength than stainless steel will enable the production of low metal density stents that may further improve the anatomical and clinical outcomes of current stainless steel stents. Drug elution from these stent platforms could further improve the outcomes in small vessels. In future, different stent designs and variable strut thickness with different drug elutions need to be tested in small coronary vessels.

\section{Conclusion}

We have reviewed balloon angioplasty and the placement of BMS and different DESs in small vessels with respect to clinical outcomes. We could conclude that (1) small vessel coronary angioplasty is common; (2) DES considerably reduces the incidence of angiographic restenosis and TLR as compared with BMS; and (3) a trend is observed with regard to better angiographic and clinical outcomes of EES and SES over PES and ZES but with similar safety profile. Stent design and strut thickness along with DES influence the outcomes in small coronary vessels similar to other coronary lesions.

Large size, randomized, controlled, double-blinded multicenter trials with long-term follow-up are needed to evaluate different DESs and designs in small vessel CAD.

\section{Disclosure}

The author reports no conflicts of interest in this work.

\section{References}

1. Mackay J, Menash G. The Atlas of Heart Disease and Stroke. Geneva, Switzerland: World Health Organisation, Centers for Disease Control and Prevention; 2004.

2. Wong P, Lau KW, Lim YL, Oesterele SN. Stent placement for nonSTRESS/BENESTENT lesions: a critical review. Catheter Cardiovasc Interv. 2000;51:223-233.

3. O'Connor NJ, Morton JR, Birmeyer JD, Olmstead EM, O'Connor GT; Northern New England Cardiovascular Disease Study Group. Effect of coronary artery diameter in patients undergoing coronary bypass surgery. Circulation. 1996;93:652-655.

4. Bauters $\mathrm{C}$, Hubert E, Prat A, et al. Predictors of restenosis after coronary stent implantation. J Am Coll Cardiol. 1998;31:1291-1298.

5. Serruys PW, Kay IP, Disco C, et al. Periprocedural quantitative coronary angiography after Palmaz-Schatz stent implantation predicts the restenosis rate at six months: results of a meta analysis of the Belgian Netherlands Stent study (BENESTENT) I, BENESTENT II Pilot, BENESTENT II and MUSIC trials. Multicenter ultrasound stent in coronaries. J Am Coll Cardiol. 1999;34:1067-1074. 
6. Serruys PW, de Jaegere P, Kiemeneij F, et al. A comparison of balloon-expandable stent implantation with balloon angioplasty in patients with coronary artery disease. Benestent Study Group. N Engl J Med. 1994;331:489-495.

7. Fischman DL, Leon MB, Baim DS, et al. A randomised comparison of coronary-stent placement and balloon angioplasty in the treatment of coronary artery disease. Stent Restenosis Study Investigators. $N$ Eng $J$ Med. 1994;331:496-501.

8. Macaya C, Serruys PW, Ruygrok P, et al. Continued benefit of coronary stenting versus balloon angioplasty: one year clinical follow up of Benestent Study Group. J Am Coll Cardiol. 1996;27:255-261.

9. Betriu A, Masotti M, Sera A, et al. Randomised comparison of coronary stent implantation and balloon angioplasty in the treatment of de novo coronary artery lesions (START): a four-year follow-up. $J$ Am Coll Cardiol. 1999;34:1498-1506.

10. Keimeneij F, Serruys PW, Macaya C, et al. Continued benefit of coronary stenting versus balloon angioplasty: five-year clinical follow up of Benestent-I trial. J Am Coll Cardiol. 2001;37:1598-1603.

11. Kastrati A, Schomig A, Dirschinger J, et al. A randomised trial comparing stenting with balloon angioplasty in small vessels in patients with symptomatic coronary artery disease. ISAR-SMART Study Investigators. Intracoronary stenting or angioplasty for restenosis reduction in small arteries. Circulation. 2000;102:2593-2598

12. Park SW, Lee CW, Hong MK, et al. Randomized comparison of coronary stenting with optimal balloon angioplasty for treatment of lesions in small coronary arteries. Eur Heart J. 2000;21: 1785-1789.

13. Koning R, Eltchaninoff H, Commeau P, et al. Stent placement compared with balloon angioplasty for small coronary arteries: in-hospital and 6-month clinical and angiographic results. Circulation. 2001;104: 1604-1608.

14. Moer R, Myreng Y, Molstad P, et al. Stenting in small coronary arteries (SISCA) trial. A randomised comparison between balloon angioplasty and the heparin-coated stent. J Am Coll Cardiol. 2001;38: 1598-1603.

15. Mauri L, Orav EJ, Kuntz RE. Late loss in lumen diameter and binary restenosis for drug-eluting stent comparison. Circulation. 2005;111: 3435-3442.

16. Meir B, Sousa E, Guagliumi G, et al. Sirolimus-eluting coronary stents in small vessels. Am Heart J. 2006;151:1017el-1019e1.

17. Ellis SG, Popma JJ, Lasala JM, et al. Relationship between angiographic late loss and target lesion revascularization after coronary stent implantation: analysis from the TAXUS-IV trial. $\mathrm{J}$ Am Coll Cardiol. 2005;45:1193-1200

18. Agostoni P, Biondi-Zoccai GL, Gasparani GL, et al. Is bare-metal stenting superior to balloon angioplasty for small vessel coronary artery disease? Evidence from a meta-analysis of randomised trials. Eur Heart J. 2005;26:881-889.

19. Doucet C, Schalij MJ, Vrolix MC, et al. Stent placement to prevent restenosis after angioplasty in small coronary arteries. Circulation. 2001;104:2029-2033.

20. Haude M, Konorza TF, Kalnins U, Erglis A, et al. Heparin-coated stent placement for the treatment of stenosis in small coronary arteries of symptomatic patients. Circulation. 2003;107:1265-1270.

21. Kinsara AJ, Niazi K, Patel I, Amoudi O. Effectiveness of stents in small coronary arteries. Am J Cardiol. 2003;92:584-587.

22. Hanekamp C, Koolen J, Bonnier H, et al. Randomised comparison of balloon angioplasty versus silicon carbon-coated stent implantation for de novo lesions in small coronary arteries. Am J Cardiol. 2004;93:1233-1237.

23. Garcia E, Gomez-Reico M, Moreno R, et al. Stent reduces restenosis in small vessels. Results of the RAP study [abstract]. J Am Coll Cardiol. 2001;37:17A.

24. Muramatsu T, Iwasaki K, Inou N, et al. Efficacy of coronary stenting versus balloon angioplasty in vessels of diameter less than $3.0 \mathrm{~mm}$ and less than $2.5 \mathrm{~mm}$ : CHIVAS investigators [abstract]. Am J Cardiol. 2002; 90:96H.
25. Hausleiter J, Kastrati A, Mehelli J, et al. A randomised trial comparing phosphorylcholine-coated stents with balloon angioplasty in small coronary arteries in patients with symptomatic coronary artery disease. The ISAR-SMART 2 Trial [abstract]. Circulation. 2003;108:IV-569.

26. Rodriguez AE, Rodriguez-Alemparte MJ, Pereira CF, et al. Final angiographic and clinical results of the Latin America small vessel randomised study (LASMAL trial) [abstract]. J AM Coll Cardiol. 2003; 41:26A.

27. Rodriguez A. LASMAL-II: a prospective randomised trial of phosphorylcholine-coated stenting vs balloon angioplasty in small vessels in the diabetic patient (featured lecture). TCT 2003. Available from: http://www.tctmd.com/expert-presentations. Accessed 2004 Jun 27.

28. Stone GW, Ellis SG, Cox DA, et al. One-year clinical results with the slow-release, polymer based, paclitaxel-eluting TAXUS stent: the TAXUS-IV trial. Circulation. 2004;109:1942-1947.

29. Stone GW, Ellis SG, Canon L, et al. Comparison of a polymer-based paclitaxel-eluting stent with a bare metal stent in patients with complex coronary artery disease: a randomised controlled trial. JAMA. 2005;294:1215-1223.

30. Dawkins KD, Grube E, Guagliumi G, et al. Clinical efficacy of polymer-based paclitaxel-eluting stents in the treatment of complex, long coronary artery lesions from a multicenter, randomised trial: support for the use of drug-eluting stents in contemporary clinical practice. Circulation. 2005;112:3306-3313.

31. Holmes DR Jr, Leon MB, Moses JW, et al. Analysis of 1-year clinical outcomes in the SIRIUS trial: a randomised trial of a sirolimus-eluting stent versus a standard stent in patients at high risk for coronary restenosis. Circulation. 2004;109:634-640.

32. Popma JJ, Leon MB, Moses JW, et al. Quantitative assessment of angiographic restenosis after sirolimus-eluting stent implantation in native coronary arteries. Circulation. 2004;110:3773-3780.

33. Ardissino D, Cavallini C, Bramucci E, et al. Sirolimus-eluting vs uncoated stents for prevention of restenosis in small coronary arteries: a randomised trial. JAMA. 2004;292:2727-2734.

34. Lee CW, Suh J, Lee SW, et al. Factors predictive of cardiac events and restenosis after sirolimus-eluting stent implantation in small coronary arteries. Catheter Cardiovasc Interv. 2007;69:821-825.

35. Fajadet J, Wijns W, Laarman GJ, et al. Randomised, double-blind, multicenter study of the Endeavor zotralimus-eluting phosphorylcholine-encapsulated stent for the treatment of native coronary artery lesions: clinical and angiographic results of the ENDEAVOR II Trial. Circulation. 2006;114:798-806.

36. Mehilli J, Dibra A, Kastrati A, et al. Randomised trial of paclitaxeland sirolimus-eluting stents in small coronary vessels. Eur Heart $J$. 2006;27:260-266.

37. Togni M, Eber S, Widmer J, et al. Impact of vessel size on outcome after implantation of sirolimus-eluting and paclitaxel-eluting stents: a sub-group analysis of the SIRTAX Trial. J Am Coll Cardiol. 2007;50:1123-1131.

38. Park KH, Park SW, Hong MK, et al. Comparison of the effectiveness of sirolimus- and paclitaxel-eluting stents for small coronary artery lesions. Catheter Cardiovasc Interv. 2006;67:589-594.

39. Rodriguez-Granillo GA, Valgimigli M, Garcia-Garcia HM, et al. Oneyear clinical outcome after coronary stenting of very small vessels using $2.25 \mathrm{~mm}$ sirolimus- and paclitaxel-eluting stents: a comparison between the RESEARCH and T-SEARCH registries. J Invasive Cardiol. 2005;17:409-412.

40. Tanimoto S, Daemen J, Tsuchida K, et al. Two-year clinical outcome after coronary stenting of small vessels using $2.25 \mathrm{~mm}$ sirolimus- and paclitaxel-eluting stents: insight into the RESEARCH and T-SEARCH registries. Catheter Cardiovasc Interv. 2007;69:94-103.

41. Leon MB, Mauri L, Popma JJ, et al. A randomised comparison of the Endeavor zotrolimus-eluting stent versus the TAXUS paclitaxel-eluting stent in de novo native coronary lesions: 12 month outcomes from the ENDEAVOR IV trial. J Am Coll Cardiol. 2010;55:543-554.

42. Stone GW, Rizve A, Newman W, et al. Everolimus-eluting versus paclitaxel-eluting stents in coronary artery disease. $N$ Engl $J$ Med. 2010;162:1663-1664 
43. Wykrzykowska JJ, Serruys PW, Onuma Y, et al. Impact of vessel size on angiographic and clinical outcomes of revascularization with biolimuseluting stent with biodegradable polymer and sirolimus-eluting stent with durable polymer the LEADERS trial substudy. JACC Cardiovasc Interv. 2009;2:861-870.

44. Stone GW, Midei M, Newman W, et al. Randomised comparison of everolimus-eluting and paclitaxel-eluting stents: two-year clinical follow-up from the clinical evaluation of the XIENCE V everolimuseluting coronary stent system in the treatment of patients with de novo native coronary artery lesions SPIRIT III trial. Circulation. 2009; 119:680-686.

45. Kandzari D, Leon MB, Popma JJ, et al. Comparison of zotralimus-eluting and sirolimus-eluting stents in patients with native coronary artery disease: a randomised controlled trial. ENDEAVOR III trial. J Am Coll Cardiol. 2006;48:2440-2447.

46. Mauri L, Orav EJ, Candia SC, et al. Robustness of late lumen loss in discriminating drug-eluting stents across variable observational and randomised trials. Circulation. 2005;112:2833-2839.

47. Briguori C, Sarais C, Pagnotta P, et al. In-stent restenosis in small coronary arteries: impact of strut thickness. J Am Coll Cardiol. 2002; 40:403-409.

48. Brambilla N, Morici N, Bedogni F, et al. Thin strut chrome-cobalt stent implantation for treatment of de-novo lesions in small coronary vessels: results of the RISCO Italian registry utilizing the Mini VISION coronary stent platform. J Cardiovasc Med (Hagerstown). 2009;10: $852-858$.
49. Turco MA, Ormiston JA, Poma JJ, et al. Reduced risk of restenosis in small vessels and reduced risk of myocardial infarction in long lesions with the new thin-strut TAXUS Liberte stent: 1-year results from the TAXUS ATLAS program. JACC Cardiovasc Interv. 2008;1:699-709.

50. Karrillon GJ, Morice MC, Benveniste E, et al. Intracoronary stent implantation without ultrasound guidance and with replacement of conventional anticoagulation by antiplatelet therapy. 30-day clinical outcome of the French multicenter registry. Circulation. 1996;94: 1519-1527.

51. Mak KH, Belli G, Ellis SG, et al. Subacute stent thrombosis: evolving issues and current concepts. J Am Coll Cardiol. 1996;27:494-503.

52. Moussa I, Di Mario C, Reimers B, et al. Subacute stent thrombosis in the era of intravascular ultrasound-guided coronary stenting without antocoagulation: frequency, predictors and clinical outcome. J Am Coll Cardiol. 1997;29:6-12.

53. Akiyama T, Moussa I, Reimers B, et al. Angiographic and clinical outcome following coronary stenting of small vessels: a comparison with coronary stenting of large vessels. J Am Coll Cardiol. 1998;32: 1610-1618.

54. Lau KW, Ding ZP, Sim LL, et al. Clinical and angiographic outcome after angiography-guided stent placement in small coronary vessels. Am Heart J. 2000;139:830-839.

55. Kastrati A, Dirschinger J, Boekstegers P, et al. Influence of stent design on 1-year outcome after coronary stent placement: a randomised comparison of five stent types in 1,147 unselected patients. Catheter Cardiovasc Interv. 2000;50:290-297.
Vascular Health and Risk Management

\section{Publish your work in this journal}

Vascular Health and Risk Management is an international, peerreviewed journal of therapeutics and risk management, focusing on concise rapid reporting of clinical studies on the processes involved in the maintenance of vascular health; the monitoring, prevention and treatment of vascular disease and its sequelae; and the involvement of

\section{Dovepress}

metabolic disorders, particularly diabetes. This journal is indexed on PubMed Central and MedLine. The manuscript management system is completely online and includes a very quick and fair peer-review system, which is all easy to use. Visit http://www.dovepress.com/ testimonials.php to read real quotes from published authors. 